\title{
Removal of organic compounds from natural underground water in sorption and sono- sorption processes on selected activated carbons
}

\author{
Andżelika Pietrzyk ${ }^{1, *}$, and Dorota Papciak $^{1}$ \\ ${ }^{1}$ Department of Water Purification and Protection, Rzeszow University of Technology, Faculty of \\ Civil and Environmental Engineering and Architecture, Aleja Powstańców Warszawy 6, 35-959 \\ Rzeszow, Poland
}

\begin{abstract}
The article rated removal efficiency of organic matter in the processes of sorption and sono-sorption of underground water grasped for municipal purposes. The studies were conducted in laboratory scale and verified in pilot scale at the Water Treatment Plant Tarnobrzeg-Jeziórko. In the research used granular activated carbons, ie. WD-Extra, WG-12, Norit Row 0.8 and Filtrasorb 300. The processes efficiency was evaluated on the basis of changes in the following parameters, ie.: total organic carbon (TOC), permanganate index, UV absorbance, turbidity and colour. The ultrasounds were generated by means of disintegrator Sonics\&Materials VCX 130, using the sonication time of 1 and 5 minutes. The results obtained for the batch tests allowed to observe a beneficial effect of ultrasound on the efficiency of the removal of organic material in the sorption process. The combination of sonication and sorption on activated carbon increased the efficiency of the removal of organic matter by $6-37 \%$ for TOC, and $18.6-27.9 \%$ for permanganate index, depending on the sorbent used. The positive laboratory results were not confirmed in a pilot scale. In the flow conditions the sonication process did not affect the efficiency of removal of organic matter on the filter model with a bed of activated carbon.
\end{abstract}

\section{Introduction}

Effective elimination of organic contaminants is now one of the major problems encountered in water purification plants. The presence of natural organic matter (NOM), particularly humic substances in the drinking water, is a negative phenomenon causing deterioration of organoleptic properties of water as well as contributing to the formation of by-products of disinfection and oxidation [1,2]. A considerable content of organic substances in water entering the distribution system is one of the main causes of the instability of water conditioning the secondary microbial growth on the network [3,4]. The content of organic matter in natural waters is very variable and depends mainly on the type

\footnotetext{
* Corresponding author: d332@stud.prz.edu.p1
} 
of water, geographic location, temperature, salinity, $\mathrm{pH}$, microbial activity and the nature of the surrounding catchment $[5,6]$.

The unit processes used in the process of water purification systems, i.e. coagulation, adsorption, ion exchange, chemical oxidation and membrane processes, often do not provide sufficient removal of organic matter, and their efficiency largely depends on the composition of purified water, the properties of the existing NOM fractions and the conditions of the process [3].

The need to reduce the content of organic compounds in intaken waters caused an increase in interest in the methods of connecting the unit processes with chemical agents (Fenton reaction) or physical (ultrasound, UV radiation), which are designed not only to effectively eliminate organic pollutants, but also to reduce the amount used at reagent stations [7-11].

In the last decade there has been more and more interest in ultrasound process, i.e. sonosorption. Their effectiveness is confirmed by many studies. The efficiency of sono-sorption is influenced, among others, by the degree of contamination of the solution, sonification time and its intensity, and kind of activated carbon. It is worth noting that the majority of experiments conducted to date, relating to the sono-sorption process were performed on the basis of model solutions prepared on the basis of commercial preparations of humic acids, while a much smaller amount of them applies to natural waters [2, 12-14].

The aim of the research was to evaluate the possibility of using ultrasonic energy to intensify the removal of NOM from natural groundwater. The effectiveness of lowering the content of organic substances in the combined sorption and sonification processes using granular activated carbons was determined in the article.

\section{Materials and methods}

\subsection{The subject of research}

The study was carried out on the natural underground water purified at the Water Treatment Plant (WTP) Tarnobrzeg-Jeziórko. The WTP is supplied from an unconfined quaternary aquifer with a depth of about $15 \mathrm{~m} \mathrm{bgl}$ using 27 wells. The physicochemical composition of water drawn and directed to the treatment station varies greatly, because it depends essentially on the well included in the operation and the productivity. Drawn water does not meet sanitary requirements for drinking water in terms of turbidity (8-14 NTU), colour (40-100 $\mathrm{mg} \mathrm{Pt} / \mathrm{l})$, the permanganate index (11-18.1 $\left.\mathrm{mg} \mathrm{O}_{2} / \mathrm{l}\right)$, ammonium ion (1.20-1.98 $\left.\mathrm{mg} \mathrm{NH}_{4}^{+} / 1\right)$, iron (14-44 mg Fe/l) and manganese (0.74-2.58 mg Mn/l). High water colour, which correlates with the elevated permanganate index value and total organic carbon (TOC; $14-20 \mathrm{mg} \mathrm{C} / \mathrm{l}$ ), indicates the presence of water of natural organic matter that may be present in combinations of complex compounds of iron and manganese.

Although the quality of the treated water which is directed to the water supply meets the requirements of the Regulation of the Minister of Health of 13 November 2015 relating to the quality of water intended for human consumption (Journal of Law 2015, pos. 1989), research has been carried out in order to further reduce the content of organic substances in the treated water of the following composition: TOC $7-11 \mathrm{mg} \mathrm{C} / \mathrm{l}$, with a permanganate index of 4.7-5 $\mathrm{mg} \mathrm{O}_{2} / 1$ and colour of $10-16 \mathrm{mg} \mathrm{Pt} / \mathrm{l}$.

Water after filtration on anthracite-sand deposits was used in the study prior to the final process of disinfection (Fig.1) at the parameters set out in Table 1. 


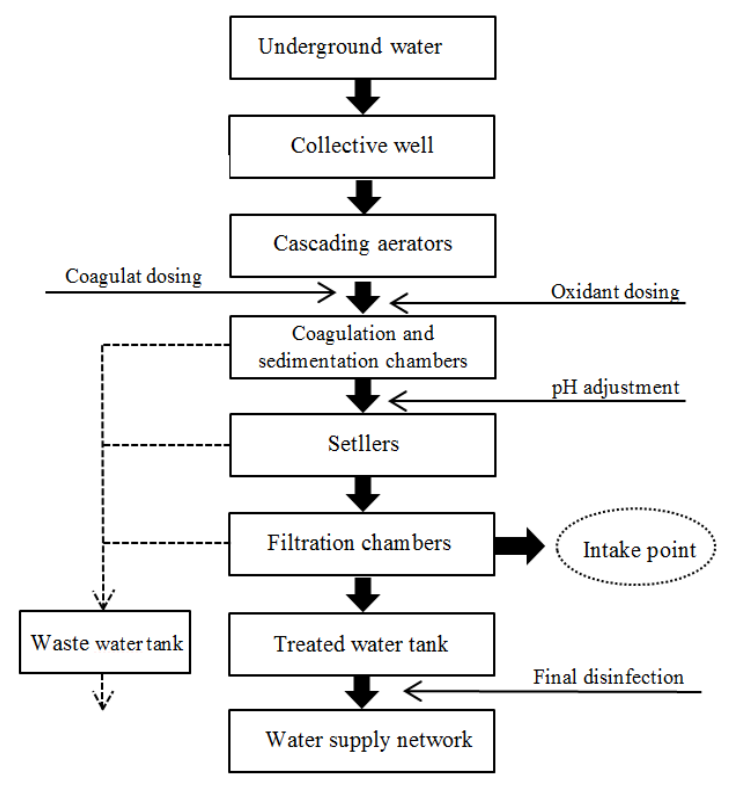

Fig. 1. Technological diagram of Water Treatment Plant.

Table 1. Physicochemical parameters of water used in the test.

\begin{tabular}{|c|c|c|} 
Parameters & Unit & Value \\
\hline TOC & $\mathrm{mg} \mathrm{C} / 1$ & 8.36 \\
\hline Absorbance UV & $254 \mathrm{~nm}, 1 \mathrm{~m}^{-1}$ & 16.46 \\
\hline Permanganate index & $\mathrm{mg} \mathrm{O}_{2} / 1$ & 4.3 \\
\hline Colour & $\mathrm{mg} \mathrm{Pt} / 1$ & 12 \\
\hline Turbidity & $\mathrm{NTU}$ & 1.08 \\
\hline
\end{tabular}

\subsection{The selection of activated carbon and determining the time of sonification}

The studies were carried out on the basis of batch tests according to the methods described in the work [14]. Adsorbent dose amounted $4 \mathrm{~g} / 1$. The prepared samples were shaken on a laboratory shaker for two hours at a speed of 140 revolutions/min, after which the samples were filtered through the coarse filter and analyzed physicochemical. The following parameters were monitored: TOC (using a TOC Sievers $5310 \mathrm{C}$ analyzer), permanganate index (by the $\mathrm{KMnO}_{4}$ method), UV absorbance and colour (using a Merck spectrophotometer) and turbidity (by nephelometry, with a Hach-Lange turbidity meter). The parameter designations were made in accordance with the test procedures.

The sonification process was carried out before process sorption using a Sonics \& Materials VCX 130 disintegrator with an amplitude of $100 \%$. The study used two exposure times: 1 and 5 minutes, the volume of sonified solution was $250 \mathrm{ml}$. The amount of energy input during the one minute sonification was about $2000 \mathrm{~J}$, whereas at 5 minutes, this value increased to approximately $11500 \mathrm{~J}$. After subjecting the water sample to ultrasound action, the sorption process was carried out.

The study used the following sorbents, i.e. WD-Extra, WG-12, Norit Row 0.8 and Filtrasorb 300. A detailed technical specification of activated carbons is presented in Table 2. The sorbents were washed with distilled water (in order to remove ash) prior to commencing the tests, and then dried at $145^{\circ} \mathrm{C}$. 
Table 2. Technical specifications of activated carbons (according to the manufacturer).

\begin{tabular}{|c|c|c|c|c|}
\hline Parameter & WG-12 & WD-Extra & Norit Row 0.8 & Filtrasorb 300 \\
\hline Ball-pan hardness & $96.4 \%$ & $97 \%$ & $98 \%$ & $95 \%$ \\
\hline Methylene blue adsorption & $33 \mathrm{~cm}^{3}$ & $30 \mathrm{~cm}^{3}$ & $24 \mathrm{~cm}^{3}$ & $28 \mathrm{~cm}^{3}$ \\
\hline Iodine number & $1074 \mathrm{mg} / \mathrm{g}$ & $998 \mathrm{mg} / \mathrm{g}$ & $\geq 1100 \mathrm{mg} / \mathrm{g}$ & $1065 \mathrm{mg} / \mathrm{g}$ \\
\hline Apparent density & $450 \mathrm{~g} / \mathrm{dm}^{3}$ & $478 \mathrm{~g} / \mathrm{dm}^{3}$ & $400 \mathrm{~g} / \mathrm{dm}^{3}$ & $480 \mathrm{~g} / \mathrm{dm}^{3}$ \\
\hline $\mathrm{pH}$ & - & 11.0 & alkaline & alkaline \\
\hline Moisture & $0.7 \%$ & - & $\leq 5 \%$ & $2 \%$ \\
\hline Ash content & $6 \%$ & - & $7 \%$ & $7 \%$ \\
\hline
\end{tabular}

\subsection{Determination of the effect of sonification on NOM removal efficiency in the sorption and bio-sorption processes}

The tests were carried out in a semi-technical scale, in the flow conditions using filtration columns with the parameters specified in Table 3. The model filters were filled with two types of activated carbon, i.e. WD-Extra and WG-12.

The model filter filled with WD-Extra granular activated carbon was incorporated to work in October 2015. Following a year of operation, a biofilm was formed on the bed which allowed the removal of organic pollutants in the bio-sorption process. The operating time of the model filter at the time of the research on the process of sono-sorption was 430 days.

A filter column with WG-12 deposit has been operating since July 2016 - (150 days), and the adsorption processes still dominate on the bed. The test water was introduced over both beds by gravity via a peristaltic pump at a rate of $1 \mathrm{~m} / \mathrm{h}$.

The sonfication process was carried out before biofiltration process, i.e. a water sample having a volume of $250 \mathrm{ml}$ was sonified for 5 minutes and collected in the reservoir; after 2 hours it was placed onto the filter beds. In this way, the toxicity of free radicals on the micro-organisms which form a biofilm was reduced.

Table 3. Parameters of the filter model.

\begin{tabular}{|c|c|c|}
\hline Operating parameters & Unit & Model filters \\
\hline Height of the carbon bed & $\mathrm{m}$ & 1.40 \\
\hline Height of the supporting layer & $\mathrm{m}$ & 0.22 \\
\hline Diameter & $\mathrm{m}$ & 0.055 \\
\hline Filtration velocity & $\mathrm{m} / \mathrm{h}$ & 1 \\
\hline Contact time & $\mathrm{h}$ & 0.5 \\
\hline
\end{tabular}

\section{Evaluation of research results}

\subsection{Batch tests}

The analysis of the results obtained shows that the degree of removal of organic contaminants measured with the parameters i.e. TOC, UV absorbance, permanganate index, and the colour was different depending on the sorbent used and sonification time.

Analyzing the changes in TOC, it was found that the efficiency of removal of organic compounds in the classical sorption ranged from 19.5\% (WG-12) to $45.3 \%$ (Filtrasorb 300). As a result of sonification, the efficiency of NOM removal from the tested water increased. As a result of 5 minutes exposure of the sample to ultrasound, we observed a $55 \%$ reduction in organic content in the tested water. The exception was only the 
WD-Extra activated carbon for which the removal efficiency reached $33.9 \%$. The results indicate thereby, that the ultrasound disintegration had no significant effect on the sorption process using WD-Extra (there was a slight increase in the efficiency by only $2 \%$ (1minute) and $6 \%$ (5 minutes). However, in the case of WG-12 employing the process of sonification, the efficiency increased by $27.3 \%$ (1minute) and $37.1 \%$ (5 minutes) (Fig. 2).

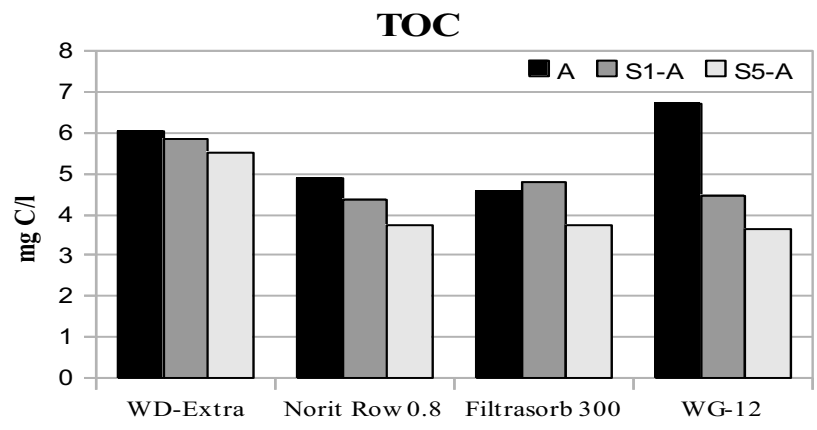

Fig. 2. Change of the TOC value in the tested water (A - adsorption, sono-sorption:

S1-A - sonification (1minute) + adsorption, S5-A - sonification (5 minute) + adsorption).

The greatest reduction in permanganate index was in the case of WG-12 activated carbon. As a result of classical sorption, the content of organic matter decreased to a value of $2.4 \mathrm{mg} \mathrm{O} / 2$, whereas the sonification process made it possible to reach the level of $1.2 \mathrm{mg} \mathrm{O} / 1$ ( 5 minutes). The effectiveness of the processes amounted to $44.2 \%$ and $72.1 \%$ respectively. The lowest efficiency of NOM removal expressed by permanganate index was reported for WD-Extra. In this case, the use of 1 minute sonification did not yield any results and the prolonged sonification time allowed the value of permanganate index only to be reduced to $2.6 \mathrm{mg} \mathrm{O}_{2} / 1$. The Filtrasorb 300 and Norit Row 0.8 were characterized by comparable efficiency to remove organic matter from the tested water; the value of permanganate index during 5-minute sonification was reduced to $1.9-2.1 \mathrm{mg} \mathrm{O}_{2} / 1$ (Fig. 3).

The UV absorbance is another parameter closely related to the structure of organic compounds. In analyzing changes in this parameter, it was found that activated carbons such as WG-12, Norit Row 0.8 and Filtrasorb 300 are characterized by similar sorption properties. The efficiency of the processes carried out for these sorbents oscillated between $62.2-67.7 \%$, while for the WD-Extra was lower and amounted to $43.5-51.3 \%$. In the case of absorbance, the sonification of the tested water did not contribute to the intensification of sorption (Fig. 3).
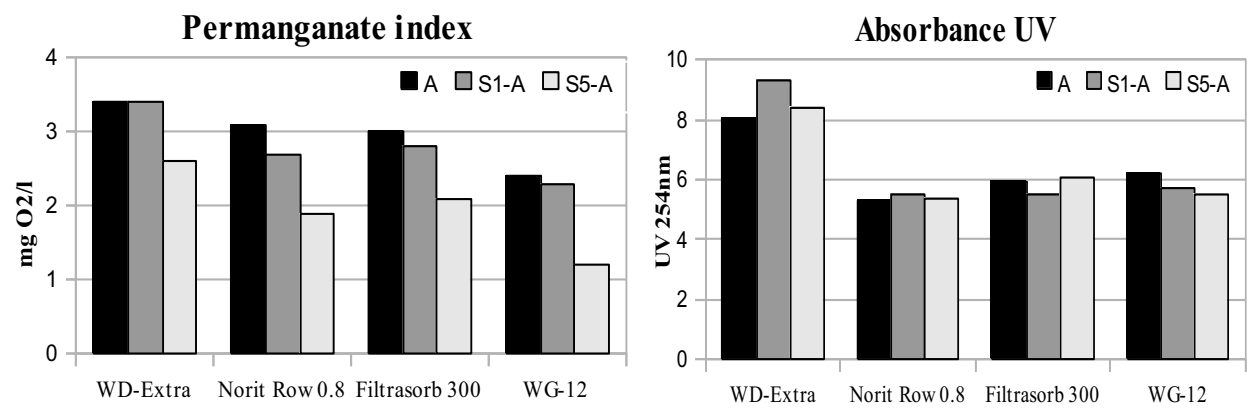

Fig. 3. Change of the permanganate index and UV absorbance value in the tested water (A - adsorption, sono-sorption: S1-A - sonification (1minute) + adsorption, S5-A - sonification (5minute) + adsorption) . 
The literature data shows that in the majority of studies carried out so far, there was no increase in sono-sorption effectiveness expressed by absorbance observed either. Subjecting the adsorbate to ultrasonic modification results in forming compounds with a specific structure, which additionally absorbs radiation thereby increasing the value of this parameter $[2,14]$. This phenomenon is identified with a simultaneous increase in turbidity, which was also confirmed in the study.

As a result of the sorption process in all the analyzed samples, reduction in the colour of the test water occurred. Most preferred changes were observed for WG-12 (efficiency reached 50\%), whereas the degree of colour reduction ranged from 16.7 to $33 \%$ in the other sorbents. Assisting the sorption process with ultrasound adversely affects the colour of water (Fig. 4).

The sorption and sono-sorption process, regardless of the adsorbent, contributed to the increase in turbidity of the tested water. The increased turbidity of solutions which have been subjected to ultrasound action may be caused by aggregation of cleaved fragments of organic compounds [2]. Whilst shaking the samples, abrasion of grains of activated carbons occurs and as a result the solution a certain amount of organic carbon, ash or other components of the sorbent can pass to solution.
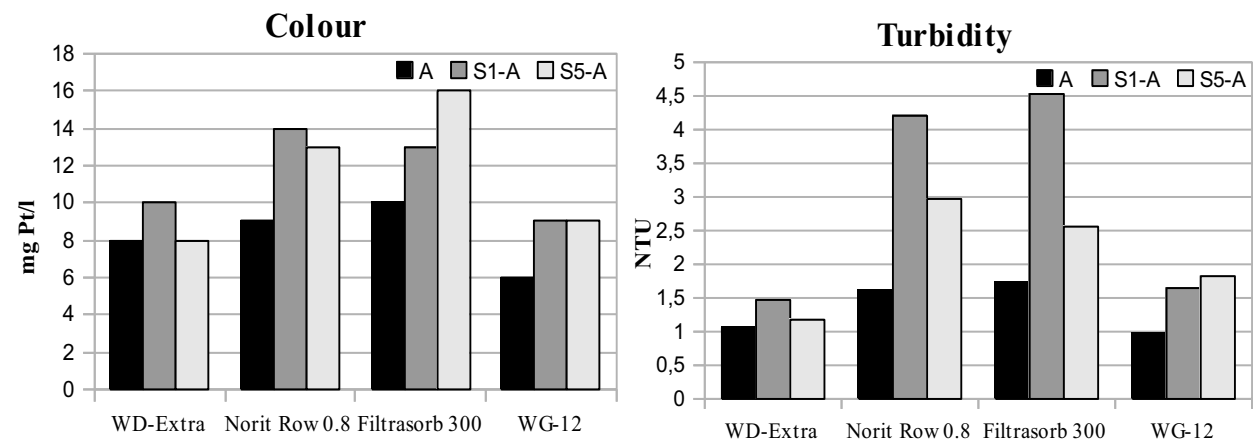

Fig. 4. Change of the colour and turbidity value in the tested water (A - adsorption, sono-sorption: S1-A - sonification (1minute) +adsorption, S5-A - sonification (5minute)+adsorption).

The research on the effectiveness of sonification shows that the ultrasonic field has a beneficial effect on the course of sorption process under laboratory conditions. The best efficiency of removal of organic compounds, expressed as TOC and permanganate index, was observed for the sono-sorption process with a sonification time of 5 minutes. A prolonged exposition time of the sample to ultrasound greatly improved the efficiency of the sorption process (e.g. for WG-12 the value of TOC and permanganate index additionally decreased by 37 and $28 \%$ respectively). The negative effect of the sonification process is visible while the increase in turbidity and colour of the tested water, and the highest values of these two parameters were recorded for Norit Row 0.8 and Filtrasorb 300.

The activated carbons used in the study were characterized by different sorption properties, as evidenced by the varied effectiveness of conducted of sorption and sonosorption processes. The ability of the sorbent to adsorb pollutants is conditioned by, among others, pore structure (the number of micro-, meso- and macropores), the size of the surface area and the amount and type of impurities present.

In the test conducted, among all analyzed activated carbons, the best removal efficiency of NOM was marked by WG-12 characterized by a high proportion of macropores. As a result of the sonification process alongside with a significant reduction in the TOC, 
permanganate index and UV absorbance, the lowest increase in colour and turbidity also occurred.

Studies carried out on model humic solutions indicate that the use of ultrasonic disintegration is particularly advantageous in the case of sorbents with a large share of microspores. The literature data indicate that activated carbons with a predominant amount of pores, the size of less than $0.2 \mu \mathrm{m}$, can have lower removal efficiency of macromolecular organic compounds, because they are not able to adsorb impurities present in the water [14].

\subsection{Flow conditions}

The model filters filled with activated carbon have a great efficacy in the removal of organic matter.

As a result of filtration of the water sample through a bed of WD-Extra (biologically activated deposit) the TOC values decreased by $25.4 \%$, permanganate index by $35.7 \%$, the UV absorbance of $39.2 \%$ and colour by $70 \%$. However, in the case of WG-12 (the bed is dominated by adsorption processes) the reduction of the analyzed indicators was $62 \%$ - TOC, 59.5\% - permanganate index, 67\% - UV absorbance and 100\% - colour respectively.

Earlier studies conducted at a water treatment plant show also that the expansion of the technological process of second degree filtering on biologically activated carbon filters greatly increases the efficiency of removal of organic matter [15].

The tests performed in a semi-technical scale on model carbon filters using the sonification process before biofiltration process did not confirm the results obtained in the batch tests - there was no increase in the efficiency of removal of organic compounds. In further studies there is a need to verify whether the lack of results is not conditional upon, among others, too low intensity of the ultrasound field, insufficient sonification time or contact time (Tab. 4).

Literature reports indicate that the use of the sonification process prior to the introduction of treated water on the filter bed can also contribute to the reduction of organic matter by creating adsorbed compounds more easily, biodegradable and better absorbed by the microorganisms forming the biological membrane [12]. The efficacy of the process may significantly be determined by the susceptibility of organic compounds to ultrasound, predominantly present in the analyzed waters. Therefore, further research will be focused on the determination of specific NOM fractions contained in the groundwater.

Table 4. The efficiency of removal of organic substances on model carbon filters.

\begin{tabular}{|c|c|c|c|c|c|c|}
\hline \multirow{2}{*}{ Parameter } & \multirow{2}{*}{ Unit } & \multirow{2}{*}{$\begin{array}{c}\text { The water } \\
\text { supply to } \\
\text { the filter }\end{array}$} & \multicolumn{2}{|c|}{ The water at the outlet of the model filters } \\
\cline { 5 - 7 } & & $\begin{array}{c}\text { Biofiltration } \\
\text { process }\end{array}$ & $\begin{array}{c}\text { Sonication } \\
\text { and } \\
\text { biofiltration } \\
\text { process }\end{array}$ & $\begin{array}{c}\text { Wiofiltration } \\
\text { process }\end{array}$ & $\begin{array}{c}\text { Sonication } \\
\text { and } \\
\text { biofiltration } \\
\text { process }\end{array}$ \\
\hline TOC & $\mathrm{mg} \mathrm{C} / 1$ & 7.93 & 5.92 & 5.88 & 3.01 & 2.92 \\
\hline Perman. index & $\mathrm{mg} \mathrm{O}_{2} / 1$ & 4.2 & 2.7 & 2.6 & 1.7 & 1.6 \\
\hline Absorbance UV & $254 \mathrm{~nm}^{-1} 1 \mathrm{~m}^{-1}$ & 15.52 & 9.44 & 10.08 & 5.12 & 5.16 \\
\hline Colour & $\mathrm{mg} \mathrm{Pt} / 1$ & 10 & 3 & 6 & 0 & 0 \\
\hline
\end{tabular}




\section{Conclusions}

1. The organic matter present in natural underground water was removed with varying efficiency depending upon the specific type of granular activated carbon, and the process (sorption, sono-sorption).

2. The application of the phenomenon of ultrasonic cavitation positively influenced the course of the sorption process in laboratory conditions. The best efficiency of removal of organic compounds, expressed as TOC and permanganate index was observed for the sono-sorption process with a sonification time of 5 minutes. A prolonged exposure time of the sample to ultrasound increased the removal efficiency of NOM removal by $6-37 \%$ for TOC, and $18.6-27.9 \%$ for the permanganate index depending on the sorbent. The WG-12 was activated carbon for which the greatest intensification of the sorption process was found.

3. A negative effect of the use of sonification process was an increase in turbidity and colour of the water sample. The highest values of these parameters were recorded for the Norit Row 0.8 and Filtrasorb 300 during 1 minute sonification time.

4. The research carried out in a semi-technical scale did not confirm the results obtained in the laboratory conditions. The application of the sonification process prior to filtration on granular activated carbons did not affect the efficiency of removal of organic contaminants. No visible results may be conditioned, among others, by insufficient intensity of ultrasound field sonification time, or contact time.

5. The effectiveness of the sono-sorption process depends on the susceptibility of organic compounds to ultrasound action; so further research will be focused on the determination of the NOM fraction contained in the groundwater.

\section{References}

1. A. Urbanowska, M., Kabsch-Korbutowicz, Environ. Prot. Eng.,vol.42, no. 2 (2016)

2. V. Naddeo, V. Belgiorno, R.M.A. Napoli, Desalination 210 (2007)

3. M. Wolska, Environ. Prot. Eng., vol. 41, no. 2 (2015)

4. W. Liu, H. Wu, Z. Wang, S.L.Ong, J.Y. Hu, W.J. Ng, Water Res. 36 (2002)

5. A. Matilainen, E. T. Gjessing, T. Lahtinen, L. Hed, A. Bhatnagar, M. Sillanpää, Chemosphere 83 (2011)

6. A. Pietrzyk, D. Papciak, JCEEA, vol. 33, no. 63 (2016) (In Polish)

7. A. Durán, J. M. Monteagudo, A. J. Expósito, V. Monsalve, Chem. Eng J. 284 (2016)

8. L.J. Xu, W. Chu, N. Graham, Water Res. 47 (2013)

9. F. Chemat, P.G.M. Teunissen, S. Chemat, P. V. Bartels, Ultrason. Sonochem. 8 (2001)

10. C. G. Joseph, G. L. Puma, A. Bono, D. Krishnaiah, Ultrason. Sonochem. 16 (2009)

11. M. Sillanpaa, Natural Organic Matter in Water (IWA Publishing, 2015)

12. P. Olesiak, L. Stępniak, Acta. Biochim. Pol., vol. 61, no. 4 (2014)

13. L. Stępniak, M. Kusiak, E. Okoniewska, Rocz Ochr Sr, vol. 15 (2013) (In Polish)

14. M. Kusiak, L. Stępniak, Inżynieria Środowiska-Młodym Okiem, vol. 1 (2012) (In Polish)

15. D. Papciak, J. Kaleta, A. Puszkarewicz, B. Tchórzewska-Cieślak, J. Eco. Eng., vol. 17, no. 3 (2016) 